\title{
Safety and efficacy of pirfenidone in patients carrying telomerase complex mutation
}

\author{
To the Editor:
}

The most frequent mutations in familial pulmonary fibrosis (FPF) involve genes of the telomerase complex such as TERT, TERC, RTEL1, PARN or DKC1 [1]. Mutations within TERT and TERC are found in $15-20 \%$ of FPF and are associated with blood, liver and skin disorders. Idiopathic pulmonary fibrosis (IPF) is the most frequent multidisciplinary diagnosis in TERT and TERC mutation carriers $[1,2]$. Treatment of IPF in patients who carry a TERT or TERC mutation has not been previously defined. Recently, danazol, a synthetic androgen, was shown to increase telomere length, and seemed to stabilise forced vital capacity (FVC) and diffusing capacity of the lung for carbon monoxide (DLCO) in telomerase complex mutation carriers [3]. Pirfenidone has been shown to reduce FVC decline and to improve progression-free survival in IPF $[4,5]$; however, pirfenidone has not been specifically evaluated in telomerase complex mutation carriers. The aim of this multicentre retrospective study was to evaluate the safety and efficacy of pirfenidone in patient carriers of TERT/TERC mutations.

All patients from France, Athens (Greece) and Barcelona (Spain) with pulmonary fibrosis and a pathogenic mutation within TERT and TERC, who received at least one dose of pirfenidone, were included in the study. We collected clinical status data, self-reported adherence, adverse events and pulmonary function test results, at initial diagnosis, at pirfenidone initiation, and at each visit up to pirfenidone stopping or the last follow-up visit. Disease progression was defined by an acute exacerbation [6] or a relative decrease of FVC $>10 \%$ or a relative decrease of DLCO $>15 \%$ compared to baseline. In order to assess pirfenidone efficacy, we compared the rate of FVC and DLCO decline before and after treatment initiation, using a nonlinear mixed effect model [7]. Random-coefficient models with a random intercept and a random slope were fitted to assess the rate of change in the main parameters (FVC in litres, FVC as $\%$ predicted and DLCO as \% predicted) over the study period. In these models, interaction of pirfenidone treatment and time were introduced in the model to assess the impact of treatment on the rates of change over time. The random slopes were based on time of lung function test assessment. Effect estimates were adjusted for sex and age at study entry. Deaths and drop-outs were considered as missing data. No attempt was made to impute missing data. Annualised declines in the main parameters were assessed by the empirical Bayes estimates. The R software (3.0.2) (www.r-project.org) was used together with the "nlme" package.

We identified 33 patients meeting the inclusion criteria, including 12 patients previously reported [1]. Among them 21 had a familial history of interstitial lung disease (ILD) and/or liver cirrhosis and/or haematological disease. All the patients had a pulmonary fibrosis, including 31 (93.9\%) IPF, one (3.0\%) rheumatoid arthritis-ILD and one (3.0\%) pleuropulmonary fibroelastosis. 13 (39.3\%) patients had blood abnormalities and $10(30.3 \%)$ patients showed liver abnormalities.

The follow-up data were available for all patients at 3 and 6 months (figure 1a). 24 patients were male and the mean \pm SD age at diagnosis was $59.8 \pm 6.0$ years. 31 patients carried a TERT mutation and two patients carried a TERC mutation. At treatment initiation, the mean \pm SD FVC was $78.6 \pm 17.1 \%$ of the predicted value and the mean \pm SD DLCO value was $46.6 \pm 15.7 \%$ of the predicted value. The median survival time was 5.76 years (range: $0.25-8.42$ years) and the median transplant-free survival time was 3.0 years (range: 0.25-7.00 years). During follow-up the mean \pm SD FVC decline was $314.5 \pm 107.6 \mathrm{~mL}$ per year. Eight patients

@ERSpublications

In this retrospective study, a beneficial effect of pirfenidone on lung function decline could not be demonstrated in patients carrying TERT/TERC mutation http://ow.ly/VYpJ30i5wSr

Cite this article as: Justet A, Thabut G, Manali E, et al. Safety and efficacy of pirfenidone in patients carrying telomerase complex mutation. Eur Respir J 2018; 51: 1701875 [https://doi.org/10.1183/ 13993003.01875-2017]. 
a)
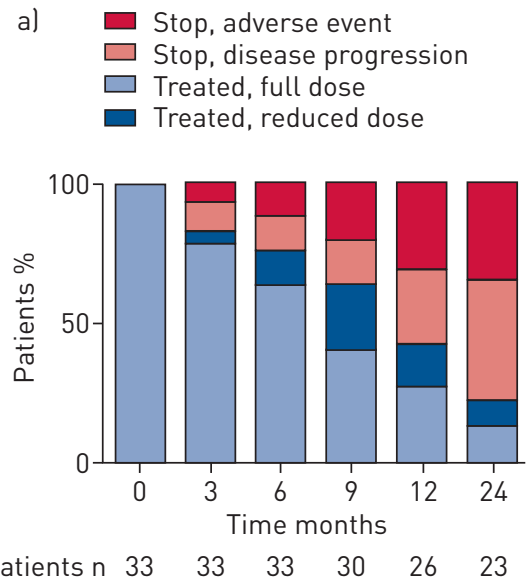

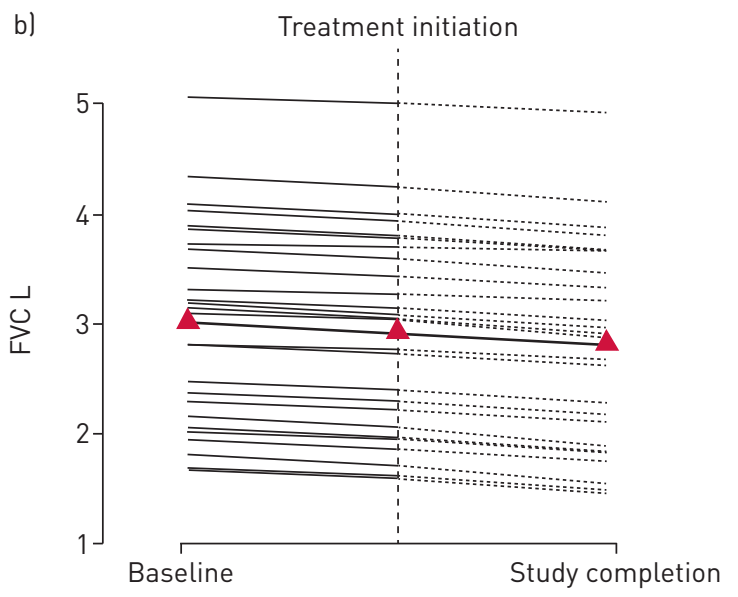

FIGURE 1 a) Adherence to treatment and cause of discontinuation. The numbers at the bottom represent the number of patients with available data at each time. b) Model of annualised decline of forced vital capacity (FVC) before (solid lines) and after (dotted lines) pirfenidone initiation. Red triangles indicate the mean FVC.

experienced an acute exacerbation, four patients received lung transplantation and nine patients died, all from respiratory failure, all of them where then considered as progressors.

The median time between diagnosis and treatment initiation was 10.1 months (range: 0-66.5 months) and the median duration of treatment was 237 days (range: 31-1461 days). After 3 months, 27 (81.8\%) out of 33 patients still received pirfenidone, including 26 at the full dose ( $2403 \mathrm{mg}$ daily). One year after pirfenidone initiation, 15 (57.7\%) out of 26 patients had stopped the treatment, including seven $(26.9 \%)$ due to disease progression and eight (31\%) because of adverse events or poor tolerance (figure 1a).

28 patients $(84.8 \%)$ experienced at least one adverse event, including gastro-oesophageal reflux (33.3\%), nausea (30.3\%), diarrhoea (30.3\%), weight loss (24.2\%), anorexia (24.2\%) and photosensitivity (12.1\%). Seven patients experienced adverse events leading to termination of treatment (gastrointestinal, $\mathrm{n}=2$; increased transaminases, $n=2$; weight loss, $n=1$; toxidermia, $n=2$ ). We did not observe any haematological complications in this cohort [8].

Regarding efficacy, we included in the analysis the patients who received pirfenidone for at least 3 months, i.e. $27(82 \%)$ patients. All the patients included in efficacy analysis had data available at 3 months and 6 months. At 9 months and 12 months, the data are missing for two and four patients (i.e. a total of six patients at 12 months), respectively. The median time between diagnosis and pirfenidone initiation was 9.1 months (range: $0.0-71.0$ months). The median duration of efficacy data available for this group was 10.0 months (range: 5.0-48.2 months).

Adjusted decline of FVC was $161.8 \pm 31.2 \mathrm{~mL}$ per year $(3.47 \pm 1.06 \%$ of predicted value) before and $235.0 \pm 49.7 \mathrm{~mL}$ per year $(4.65 \pm 1.06 \%$ of predicted value) after pirfenidone initiation (figure $1 \mathrm{~b})$. There was no difference between annualised FVC decline before and after treatment initiation in ultimate value $(\mathrm{p}=0.15)$ or as a percentage of predicted value $(\mathrm{p}=0.43)$. Adjusted decline of DLCO was $7.52 \pm 1.65 \%$ per year before and $9.06 \pm 1.87 \%$ per year after the initiation of pirfenidone $(p=0.12)$. There was no trend and no statistical difference between the nonprogressors $(n=14)$ and the progressors $(n=19)$ at initiation, with regards to sex, smoking status, age at diagnosis (data not shown). The median lead-time until pirfenidone initiation was 7.5 months (range: $0.0-55.0$ months) in the nonprogressors, whereas it was 10.0 months (range: 0.0-71.0 months) in the progressors $(\mathrm{p}=0.21)$.

This is the first assessment of lung function decline in patients with TERT/TERC mutation who received pirfenidone. We observed that neither FVC decline nor DLCO decline was improved by pirfenidone in patients with lung fibrosis and a TERT/TERC mutation. The safety of pirfenidone in TERT/TERC mutation carriers was similar to that observed in sporadic IPF [9]. The retrospective nature and the limited number of patients included are the major limitations of this study that preclude definitive conclusions on the safety and efficacy of pirfenidone in this population. We may presume that a larger number of patients would have allowed us to show a difference in the lead-time until pirfenidone initiation between the progressors and the nonprogressors. Another limitation of the study was the self-reported adherence. However, adverse events were similar to those observed in prospective studies and in real life cohorts of sporadic IPF [10]. Despite these limitations, similar methodology to ours was previously used in retrospective works in order to demonstrate pirfenidone efficacy $[9,11]$. Interestingly, the mean rate of FVC decline with pirfenidone in this cohort was numerically higher than that measured in the treated group in patients included in recent 
clinical trials assessing the efficacy of pirfenidone [5] and similar to that recently measured by NeWTON et al. [12] in a series of 115 patients with pulmonary fibrosis and telomerase complex mutations (mean value: $300 \mathrm{~mL}$ per year). This series confirms our previous report that patients with TERT and TERC mutation present a poor transplant-free survival [1] and suggests that patients with TERT and TERC mutation present an increased decline of FVC when compared to sporadic IPF [10].

In conclusion, a beneficial effect of pirfenidone on lung function decline could not be demonstrated in this study, highlighting the urgent need for a prospective work to validate efficacy and safety of pirfenidone in patients carrying TERT/TERC mutation.

Aurélien Justet ${ }^{1,2}$, Gabriel Thabut ${ }^{2,3}$, Effrosyni Manali ${ }^{4}$, Maria Molina Molina ${ }^{5}$, Caroline Kannengiesser $\odot^{6}$, Jacques Cadranel ${ }^{7}$, Vincent Cottin $\odot^{8}$, Anne Gondouin ${ }^{9}$, Hilario Nunes ${ }^{10}$, Eline Magois ${ }^{11}$, Cécile Tromeur ${ }^{12}$, Grégoire Prevot $^{13}$, Spyros Papiris ${ }^{4}$, Sylvain Marchand-Adam ${ }^{14}$, Anne Sophie Gamez ${ }^{15}$, Martine Reynaud-Gaubert ${ }^{16}$, Lidwine Wemeau ${ }^{17}$, Bruno Crestani ${ }^{1,2}$ and Raphael Borie $\overbrace{}^{1,2}$

${ }^{1}$ APHP, Hôpital Bichat, Service de Pneumologie A, DHU FIRE, Paris, France. ${ }^{2}$ INSERM, Unité 1152, Université Paris Diderot, Paris, France. ${ }^{3}$ APHP, Hôpital Bichat, Service de Pneumologie B, Paris, France. ${ }^{4}$ Respiratory Medicine Dept, 'Attikon' University Hospital, Athens Medical School, National and Kapodistrian University of Athens, Athens, Greece.

${ }^{5}$ Unit of Interstitial Lung Diseases, Dept of Pneumology, University Hospital of Bellvitge, Barcelona, Spain. ${ }^{6}$ APHP, Hôpital Bichat, Département de Génétique, Université Paris Diderot, Paris, France. ${ }^{7}$ APHP, Service de Pneumologie, maladies pulmonaires rares, Hôpital Tenon, Paris, France. ${ }^{8}$ Service de Pneumologie, Hôpital Louis Pradel, Université Claude Bernard Lyon 1, Lyon, France. ${ }^{9} \mathrm{CHU}$ de Besançon, Service de Pneumologie, Besançon, France. ${ }^{10}$ APHP, Service de Pneumologie, maladies pulmonaires rares, Hôpital Avicenne, Bobigny, France. ${ }^{11}$ Service de Pneumologie, Hôpital d'Amiens, Université de Picardie Jules Verne, Amiens, France. ${ }^{12}$ Université Européenne de Bretagne, UBO, EA3878 (GETBO) IFR 148, CHU de la Cavale Blanche, Département de médecine interne et de pneumologie, Brest, France. ${ }^{13}$ Service de Pneumologie, Hôpital Larrey, Toulouse, France. ${ }^{14} \mathrm{CHU}$ de Tours, Service de Pneumologie et Explorations Fonctionnelles Respiratoires, Tours, France. ${ }^{15}$ Département de Pneumologie et Addictologie, Hôpital Arnaud de Villeneuve, CHU Montpellier, Montpellier, France. ${ }^{16}$ Service de Pneumologie, Hôpital Nord, Marseille, France. ${ }^{17}$ Service de Pneumologie, CHRU de Lille, Lille, France.

Correspondence: Raphael Borie, Service de Pneumologie A, Hôpital Bichat, 46 rue Henri Huchard, 75018 Paris, France. E-mail: raphael.borie@aphp.fr

Received: Sept 142017 | Accepted after revision: Jan 042018

Published online March 15, 2018; republished April 3, 2018 with amendments to the authors' conflict of interest disclosures.

Author contributions: A. Justet, G. Thabut, B. Crestani and R. Borie conceived and designed the study; A. Justet drafted the manuscript; A. Justet, G. Thabut, E. Manali, M. Molina Molina, C. Kannengiesser, J. Cadranel, V. Cottin, A. Gondouin, H. Nunes, E. Magois, C. Tromeur, G. Prevot, S. Papiris, S. Marchand-Adam, A.S. Gamez, M. Reynaud-Gaubert, L. Wemeau and R. Borie collected the data; A. Justet, G. Thabut, B. Crestani and R. Borie analysed and interpreted the data; G. Thabut, E. Manali, M. Molina Molina, C. Kannengiesser, J. Cadranel, V. Cottin, A. Gondouin, H. Nunes, E. Magois, C. Tromeur, G. Prevot, S. Papiris, S. Marchand-Adam, A.S. Gamez, M. Reynaud-Gaubert, L. Wemeau, B. Crestani and R. Borie revised and approved the manuscript.

Conflict of interest: V. Cottin reports grants and personal fees from Actelion, Boehringer Ingelheim, Pfizer and Roche/ Intermune, grants from Bayer, Biogen, Idec, Gilead, MSD, Novartis and Sanofi, and personal fees from GSK, during the conduct of the study. A. Gondouin reports grants and personal fees from Boehringer, and grants from Roche, outside the submitted work. H. Nunes reports personal fees from Intermune, Roche, Boehringer Ingelheim and Sanofi, outside the submitted work. G. Prevot reports personal fees from Actelion, Bayer, Boehringer Ingelheim and Roche, outside the submitted work. L. Wemeau reports personal fees from Boehringer Ingelheim, Roche/Intermune, BMS and JansenCilag, during the conduct of the study. B. Crestani reports grants and personal fees from Boehringer Ingelheim, personal fees from Roche/Intermune, Sanofi, Apellis and AstraZeneca, and grants from Medimmune, during the conduct of the study. R. Borie reports personal fees from Boehringer Ingelheim, Roche and Savapharma, outside the submitted work.

Support statement: This work was supported by the Chancellerie des Universités de Paris (legs Poix) and by a grant from Roche. Funding information for this article has been deposited with the Crossref Funder Registry.

\section{References}

1 Borie R, Tabèze L, Thabut G, et al. Prevalence and characteristics of TERT and TERC mutations in suspected genetic pulmonary fibrosis. Eur Respir J 2016; 48: 1721-1731.

2 Petrovski S, Todd JL, Durheim MT, et al. An exome sequencing study to assess the role of rare genetic variation in pulmonary fibrosis. Am J Respir Crit Care Med 2017; 196: 82-93.

3 Townsley DM, Dumitriu B, Liu D, et al. Danazol treatment for telomere diseases. N Engl J Med 2016; 374: 1922-1931.

4 Noble PW, Albera C, Bradford WZ, et al. Pirfenidone in patients with idiopathic pulmonary fibrosis (CAPACITY): two randomised trials. Lancet 2011; 377: 1760-1769.

5 King TE, Bradford WZ, Castro-Bernardini S, et al. A phase 3 trial of pirfenidone in patients with idiopathic pulmonary fibrosis. N Engl J Med 2014; 370: 2083-2092.

6 Collard HR, Ryerson CJ, Corte TJ, et al. Acute exacerbation of idiopathic pulmonary fibrosis. An international working group report. Am J Respir Crit Care Med 2016; 194: 265-275.

7 Toyoda I, Matsuyama Y, Ohashi Y. Estimation and comparison of rates of change in repeated-measures studies with planned dropout. Control Clin Trials 2001; 22: 620-638. 
8 Borie R, Kannengiesser C, Hirschi S, et al. Severe hematologic complications after lung transplantation in patients with telomerase complex mutations. J Heart Lung Transplant 2015; 34: 538-546.

9 Harari S, Caminati A, Albera C, et al. Efficacy of pirfenidone for idiopathic pulmonary fibrosis: an Italian real life study. Respir Med 2015; 109: 904-913.

10 Cottin V, Maher T. Long-term clinical and real-world experience with pirfenidone in the treatment of idiopathic pulmonary fibrosis. Eur Respir Rev 2015; 24: 58-64.

11 Salih GN, Shaker SB, Madsen HD, et al. Pirfenidone treatment in idiopathic pulmonary fibrosis: nationwide Danish results. Eur Clin Respir J 2016; 3: 32608.

12 Newton CA, Batra K, Torrealba J, et al. Telomere-related lung fibrosis is diagnostically heterogeneous but uniformly progressive. Eur Respir J 2016; 48: 1710-1720.

Copyright @ERS 2018 